\title{
Elastin Accumulation in Actinic Cheilitis with Different Degrees of Epithelial Dysplasia
}

\author{
Acumulación de Elastina en Queilitis Actínica con Diferentes Grados de Displasia Epitelial \\ "Caliandra Pinto Araújo; **Flávia Caló de Aquino Xavier; **Clarissa Araújo Silva Gurgel; ${ }^{* * *}$ Eduardo Antônio Gonçalves Ramos; \\ ***** Valéria Souza Freitas; ${ }^{* * * * *}$ Caroline Brandi Schlaepfer-Sales; ${ }^{* * * * * *}$ Luciana Maria Pedreira Ramalho \& ${ }^{* * * * * * *}$ Jean Nunes dos Santos
}

ARAÚJO, C. P.; XAVIER, F. C. A.; GUGEL, C. A. S.; RAMOS, E. A. G.; FREITAS, V. S.; SCHLAEPFER-SALES, C. B.; RAMALHO, L. M. P. \& DOS SANTOS, J. N. Elastin accumulation in actinic cheilitis with different degrees of epithelial dysplasia. Int. J. Morphol., 30(2):627-633, 2012.

SUMMARY: The extracellular matrix (ECM) plays an important role in the regulation of biological events such as the development of cell migration, proliferation and differentiation. Chronic sun exposure causes changes present in the ECM of actinic cheilitis (AC), a premalignant lesion of the lower lip which helps to understand the carcinogenesis of the lip. This study aimed to investigate elastin, the main component of solar elastosis alternating current in an attempt to establish the relationship between this protein and ECM in epithelial dysplasia. Paraffin embedded tissue sections of the lesions of 35 cases of AC were analyzed by immunohistochemistry for elastin, and became the association with the degree of epithelial dysplasia and age. Highest scores of elastin (+3) was predominant in $45.7 \%$ of cases of AC, especially in cases of severe dysplasia $(n=3)$. When comparing the scores of elastin between the different grades of epithelial dysplasia showed no significant difference ( $\mathrm{P}>0.05$, Kruskal-Wallis). This study was not able to demonstrate the influence of elastin on the severity of epithelial dysplasia in AC. Additional studies on other ECM proteins must be conducted in an attempt to better understand the mechanism of malignant progression of the AC.

KEY WORDS: Matrix extracellular; Elastin; Immunohistochemistry; Actinic cheilitis.

\section{INTRODUCTION}

The extracellular matrix (ECM) is a complex and organized structure of macromolecules, consisting mainly of collagen, elastin, proteoglycans and glycoproteins. It plays an important role in regulating the cells with which it makes contact. The ECM serves as a structural mold and barrier between tissues, and also as a reservoir of growth factors that influence biological events such as cell development, migration, proliferation and differentiation (DeClerck et al., 2004).

Chronic sun exposure provokes changes in the ECM that are evident in the dermis due to remodeling of ECM constituents (DeClerck et al.). According to Wondrak et al. (2003), repetitive stimulation of the ECM proteins by solar radiation interferes with the integrity of the genome and contributes to photoaging and carcinogenesis of human skin. This excessive exposure to radiation results in the loss of cell viability, cell membrane damage and accumulation of elastotic material that replaces the normal collagen, resulting in a modified architectural pattern in sun-damaged skin known as solar elastosis (Philips et al., 2007). Therefore, the degradation of ECM macromolecules and elastosis increases the risk of developing cancers (Yano et al., 2005). Furthermore, in the tumor microenvironment the ECM is not just a physical barrier to cancer, but also acts as a reservoir for binding proteins and growth factors that interfere with tumor behavior (DeClerck et al.). The interaction between mesenchymal cells and the ECM may also be altered in tumors, and thus influence tumor proliferation and invasion (Liotta, 1984).

Actinic cheilitis (AC) is a premalignant lesion, which clinically presents as a diffuse damage in the vermilion of the lower lip, resulting from excessive exposure to solar

\footnotetext{
DDS, Dept. of Oral Pathology, Laboratory of Oral Surgical Pathology, School of Dentistry of the Federal University of Bahia, Salvador, Bahia, Brazil Adjunct Professor, Dept. of Oral Pathology, Laboratory of Oral Surgical Pathology, School of Dentistry of the Federal University of Bahia, Salvador, Bahia, Brazil Adjunct Professor, Laboratory of Pathology and Molecular Biology, Gonçalo Moniz Research Center, Oswaldo Cruz Foundation, Salvador, Bahia, Brazil

***** Adjunct Professor, Dept. of Health (Oral Pathology) of the State University of Feira de Santana, Feira de Santana, Bahia, Brazil

****** MSc, Laboratory of Pathology and Molecular Biology, Gonçalo Moniz Research Center, Oswaldo Cruz Foundation, Salvador, Bahia, Brazil

****** Adjunct Professor, Dept. of Stomatology, School of Dentistry of the Federal University of Bahia, Salvador, Bahia, Brazil

********A Associated Professor, Dept. of Oral Pathology, Laboratory of Oral Surgical Pathology, School of Dentistry of the Federal University of Bahia, Salvador, Bahia, Brazil
} 
radiation. Histologically, the superficial lamina propia presents extensive basophilic degeneration of collagen (Cavalcante et al., 2008; dos Santos et al., 2003; Markopoulos et al., 2004; Martinez et al., 2005; Rojas et al., 2004). Among other findings, the epithelial lining may display varying degrees of dysplasia ranging from a mild change to carcinoma in situ, and even invasive carcinoma (Araújo et al., 2010; Cavalcante et al.; da Silva et al., 2007; dos Santos et al.; Markopoulos et al.; Xavier et al., 2009).

Changes in the ECM occur after chronic sun exposure and their mechanisms remain unknown. In addition, little is known about the relationship between epithelial dysplasia and the system of elastic fibers (Sgarbi et al., 2010). Then, regarding that solar elastosis is present in the connective tissue of AC, and that this may contribute to carcinogenesis of the lip, the purpose of this study was to investigate elastin, the main component of solar elastosis in AC lesions, in an attempt to establish the relationship between the presence of this protein and the different degrees of epithelial dysplasia.

\section{MATERIAL AND METHOD}

After approval by the Committee for Ethical Research, 35 cases of AC were analyzed. The cases were retrieved from the archives of the Laboratory of Surgical Pathology, Faculty of Dentistry, Federal University of Bahia (FOUFBA) and the Oncology Center of Bahia (CICAN), and also from a private laboratory in the city of Salvador, Bahia, Brazil.

Histological sections for each case, stained with hematoxylin and eosin (HE) were analyzed for the main morphological features representative of the lesions. The histological criteria defined by the World Health Organization (WHO) in 2005 were used to determine the presence and degree of epithelial dysplasia. The histological grading of epithelial dysplasia was defined as: mild dysplasia, when the architectural disturbances were limited to the lower third of the epithelium, accompanied by cytologic atypia; moderate dysplasia, when the architectural disturbances spread to the middle third of the epithelium, in which case the degree of cytologic atypia may be considered; severe dysplasia, when more than two thirds of the epithelium presented architectural disorder, associated with cytologic atypia; and carcinoma in situ, when the architectural disturbance affected the entire thickness of the epithelium, accompanied by marked cytologic atypia.

Clinical data information of the lesions was obtained from the records of requests for anatomopathological examination, and included data regarding age, sex, and skin color.

Immunohistochemistry was carried out using the Streptavidin-biotin-peroxidase method (LSAB kit, Dako, Carpinteria, CA, USA) with the primary monoclonal antibody anti-elastin (BA4 clone, Novocastra, Wetzlar, Germany). To achieve this, 3m--thick sections were made from the material immersed in paraffin. The sections were deparaffinized, rehydrated, and after washing with distilled water, slides were treated for antigen retrieval in a $1 \%$ trypsin solution for 30 minutes at $37^{\circ} \mathrm{C}$. The endogenous peroxidase activity was blocked by using a $3 \%$ hydrogen peroxide solution for 30 minutes. This was followed by incubating the primary antibody anti-elastin at 1:50 dilution for 60 minutes at room temperature in a humidity chamber. Diaminobenzidine (DAB, Dako) was used to visualize the reactions. Sections were counterstained with Harris hematoxylin. The negative control consisted of replacement of the primary antibody with an antibody of the same isotype as the primary antibody. Three fragments of normal lip mucosa without solar elastosis were also studied for the purpose of comparison.

The expression of elastin was analyzed, by a single observer, in up to 10 fields at 100x magnification, and the degree of elastosis was evaluated according to the scale of values (scores +3 to 0), adapted from Fukushima et al. (2000). The elastosis score +3 corresponded to a diffuse increase of elastic fibers with mass elastosis pattern; the score +2 , was a diffuse increase of elastic fibers; the score +1 , partial increase with focal clusters of elastic fibers; the score zero, corresponded to the same characteristics as the control group. The thickness and/or fragmentation of elastic fibers were also described.

Differences between groups were evaluated using the Kruskal-Wallis test followed by Dunn's test and Fisher's exact test. In addition, in order to facilitate evaluation between scores, we considered three age groups: up to 50 years, between 50 and 60 years, and more than 60 years All statistical calculations were performed using the GraphPad Prism 4.0 program. A P value $<0.05$ was considered to be statistically significant.

\section{RESULTS}

Of the 35 cases in our sample, $21(60 \%)$ were male and 14 (40\%) female. Their age ranged between 20 and 78 years with a mean age of 54.6 years. As for skin color, 17 
cases were white, 10 were African-Caucasian descendents, and 8 cases lacked information regarding this aspect.

The histological sections revealed that AC lesions were characterized by stratified squamous epithelium with varying degrees of keratinization, predominantly orthokeratinized and hyperparakeratinized epithelial linings. Granulosis and hypergranulosis were also seen, as well as areas of acanthosis or atrophy. The lamina propria was formed by a narrow and vascularized band of dense connective tissue, in some cases separating a large area of strongly basophilic amorphous material (solar elastosis), present in all of the cases studied. Mononuclear inflammatory infiltrate and numerous tortuous blood vessels, sometimes dilated, were also present.

The evaluation of the epithelial lining for the presence and degree of epithelial dysplasia showed that of the 35 cases studied, 17 had mild dysplasia, 13 cases had moderate dysplasia, and five had severe dysplasia.

According to the expression of elastin, $16 \mathrm{AC}$ cases had a score $+3,15$ had a score +2 , and only 4 cases, a score +1 , and none of them followed the pattern of control (Fig.1).
The elastic fibers presented varying degrees of thickness, from thin to thick, and in most cases, they were fragmented. These fibers often formed a large mass as if they were lumps, and it was not possible to view their individual characteristics. In the submucosa, the elastic fibers were also expressed, but in smaller quantities, displaying the same characteristics described in the areas of elastosis, without the formation of an amorphous mass (Fig.2)

Kruskal-Wallis test revealed no significant differences between elastin scores and degrees of ED present in $\mathrm{AC}$ cases $(\mathrm{p}=0.5274)$, although scores +2 and +3 were the most frequent in thoses cases. Proportionally, the occurrence of scores were compared to the degrees of ED, no significant difference was observed ( $\mathrm{P}=0.6418$, Fisher's exact test). Although score +2 was more frequent in moderate ED cases, no significant difference was observed $(\mathrm{P}=0.0 .2779$, Fisher's exact test $)$. Furthermore, score +3 was more frequent in mild DE cases, but no significant difference was detected $(P=0.7380$, Fisher's exact test $)$

Fisher's exact test also showed no significant difference between age groups and elastin scores $(\mathrm{P}=0.6418)$.

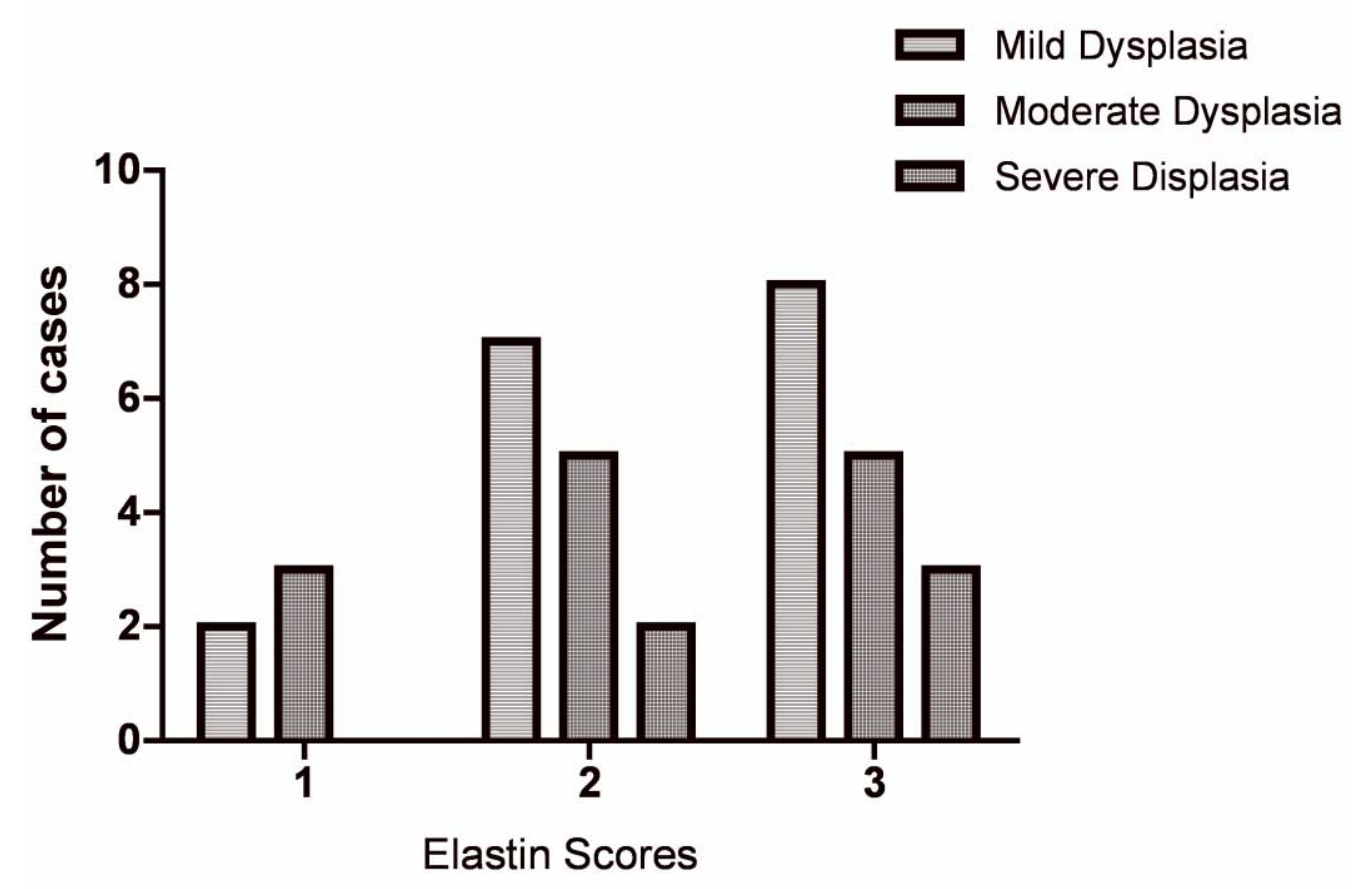

Fig. 1. Number of actinic cheilitis cases with different degrees of epithelial dysplasia according to elastin scores. 

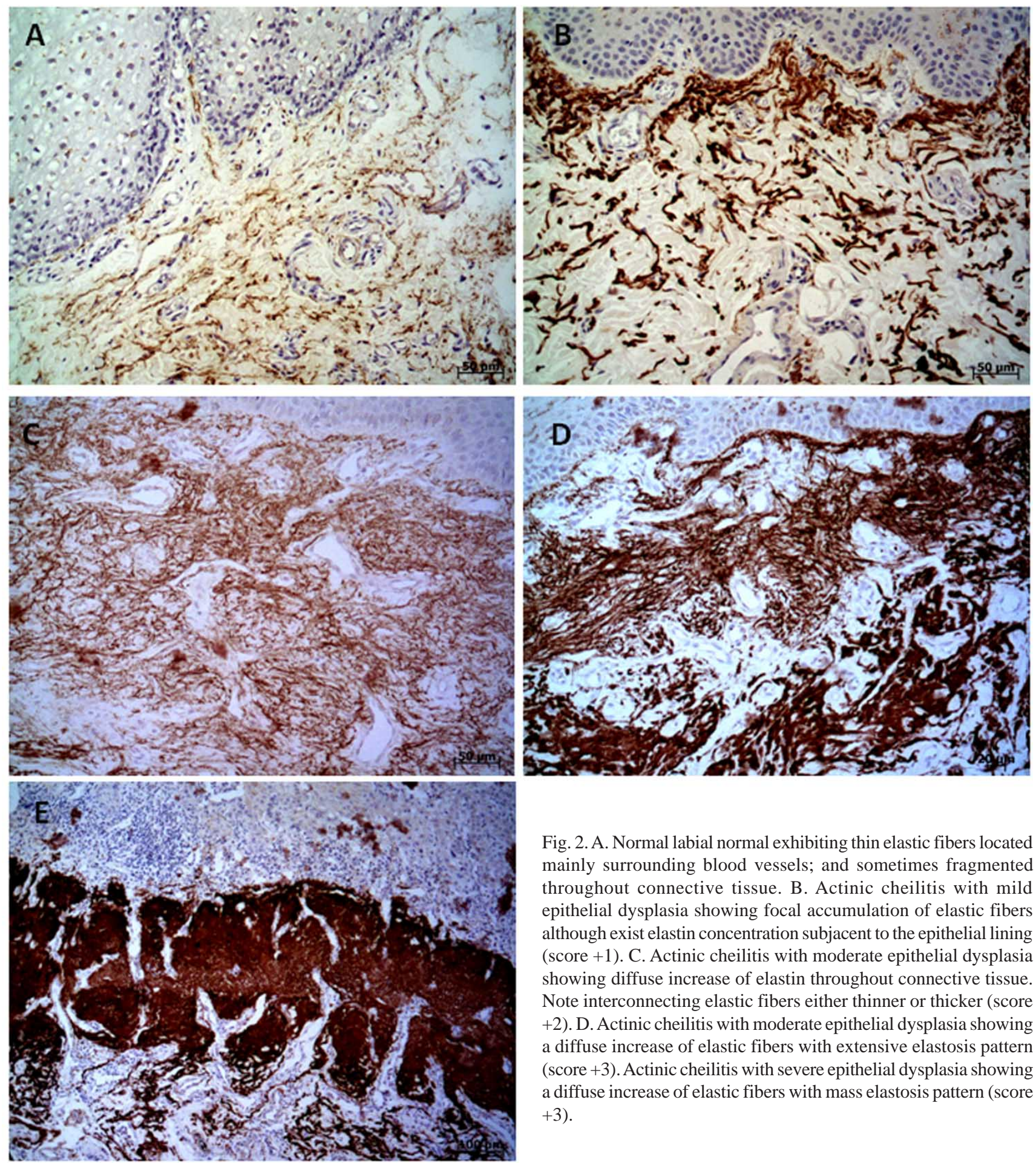

Fig. 2. A. Normal labial normal exhibiting thin elastic fibers located mainly surrounding blood vessels; and sometimes fragmented throughout connective tissue. B. Actinic cheilitis with mild epithelial dysplasia showing focal accumulation of elastic fibers although exist elastin concentration subjacent to the epithelial lining (score +1). C. Actinic cheilitis with moderate epithelial dysplasia showing diffuse increase of elastin throughout connective tissue. Note interconnecting elastic fibers either thinner or thicker (score +2 ). D. Actinic cheilitis with moderate epithelial dysplasia showing a diffuse increase of elastic fibers with extensive elastosis pattern $($ score +3$)$. Actinic cheilitis with severe epithelial dysplasia showing a diffuse increase of elastic fibers with mass elastosis pattern (score $+3)$.

\section{DISCUSSION}

A general feature of photoaged skin histology is the accumulation of elastotic material, which suggests an insufficient formation and/or deficient fragmentation of elastic fibers (Knott et al., 2009). The exact elements present 
in the elastotic material of photoinduced lesions are unknown, although various components involved in the process of elastosis have been established, including elastin, metalloproteinases, and lysozyme (Miura et al., 2004). The expression of elastin in the AC cases showed varying thickness degrees of elastic fibers, which were either fragmented or formed lumps. These elastic fibers reached the lamina propria to a great extent. Such variability could be due to Elastin Binding Proteins (EBP) and Versican (VER), regulators of elastic fiber formation, and a structural component of elastic fibers, respectively (Knott et al.).

It is argumented whether the elastic material is originated from elastic fiber synthesis or from degradation, mainly of collagen fibers (Fukushima et al.; Just et al., 2007). Others indicate that the pathogenesis of solar elastosis is attributed to the synthesis of elastic material by fibrocytes that have been altered by ultra-violet rays (UV)

Although elastosis and fragmentation of elastic fibers are components also present in natural aging, indicating that these fibers participate in the remodeling of the ECM (Just et al., 2005; Just et al., 2007), the expression of EBP and VER remains stable during aging. However, it exhibits an altered pattern of regulation during chronic exposure to UV radiation, as demonstrated by Knott et al. (Knott et al.). According to these authors, there is a consistently reduced mRNA level of VER during chronic sun exposure, despite the higher tissue protein expression found, when compared with sun-protected skin. The levels of EBP transcripts, in turn, exhibits an inverse relationship, thus suggesting the existence of a regulatory model that leads to the formation of elastotic material from altered patterns of expression of VER and EBP in skin that is chronically exposed to sunlight. The elastosis and fragmentation of elastic fibers are also components in diseases such as asthma and pulmonary emphysema as well as in smokers, indicating that these fibers participate in the ECM's remodeling process as observed in this study (Just et al., 2005; Just et al., 2007).

The stroma cells might affect adjacent epithelial cells and create an atypical microenvironment that favors the field cancerization (Ge et al., 2010). However, no relationship was found between the scores of elastosis and the different degrees of dysplasia in the AC lesions evaluated in this study. Although, in $60 \%$ severe dysplasia cases, the highest score of elastosis was found (+3). These findings corroborate the study by Sgarbi et al. in which the histochemical analysis revealed a tendency to severe dysplasia with the higher percentages of elastic fibers, while there was also significant degradation of collagen fibers in cases of moderate and severe dysplasia. Fukushima et al. and Walther et al. (2004), studying lung cancer and basal cell carcinoma respectively, correlated elastosis with the degree of tumoral invasion and, indicated that the loss of elastosis in these tumors is indicative of better prognosis. Although Sgarbi et al. did not observe significant differences in the elastic fibers accumulation between the $\mathrm{AC}$ and control groups; in contrast, we found a difference in the elastin expression pattern between both, being a higher expression in $\mathrm{AC}$ lesions.

Most of the clinical changes seen with aging result from excessive sun exposure (Seite et al., 2000; Seite et al., 2006). Many immunohistochemical studies have reported an increased deposition of non-functional elastic fibers and a correlation between the stain intensity and the extent of sun damage (Seite et al., 2006; Yano et al.). Some authors also associate angiogenesis with the alterations in elastin after UV irradiation, suggesting that angiogenesis induced by UVB mediates the damage caused by UV in the skin (Yano et al., 2005). In our findings, elastin immunoexpression revealed elastosis scores $3+$ and +2 in more than $90 \%$ of AC cases. However, elastosis showed no a positive association with advance age. However, it is important to state that previous reports show that in natural aging process and also in photoaging there is an increase in these fibers.

Although specific components of the ECM have a crucial effect on the phenotype of many diseases (Jarvelainen et al., 2009), this study was not of capable of demonstrating elastin influence on the epithelial dysplasia severity in AC. Further studies concerning other proteins in the ECM should be carried out in an attempt to better understand the mechanism of malignant progression of AC.

ARAÚJO, C. P.; XAVIER, F. C. A.; GUGEL, C. A. S.; RAMOS, E. A. G.; FREITAS, V. S.; SCHLAEPFER-SALES, C. B.; RAMALHO, L. M. P. \& DOS SANTOS, J. N. Acumulación de elastina en queilitis actínica con diferentes grados de displasia epitelial. Int. J. Morphol., 30(2):627-633, 2012.

RESUMEN: La matriz extracelular (MEC) juega un papel importante en la regulación de los eventos biológicos, tales como, el desarrollo de la migración celular, proliferación y diferenciación. La exposición solar crónica provoca cambios presentes en la MRC de la queilitis actínica (QA), una lesión premaligna del labio inferior que contribuye a entender la carcinogénesis del labio. Este estudio tuvo como objetivo investigar la elastina, el componente principal de la elastosis solar en corriente alterna en un intento de establecer la relación entre esta proteína y la MEC en displasia epitelial. Se incluyeron en parafina cortes de tejido de las lesiones de 35 casos de QC fueron analizadas mediante técnicas de inmunohistoquímica para elastina, y se hizo la asociación con los grados de displasia epitelial y la edad. La más alta puntuación de la elastina (+3) fue predominante en el $45,7 \%$ de los casos de $\mathrm{QA}$, especialmente en los casos de displasia severa $(\mathrm{n}=3)$. Al 
comparar las puntuaciones de elastina entre los diferentes grados de displasia epitelial, no mostró diferencia significativa $(\mathrm{P}>0,05$, Kruskall-Wallis). Este estudio no fue capaz de demostrar la influencia de la elastina sobre gravedad de la displasia epitelial en QA. Estudios adicionales sobre otras proteínas de la MEC deben llevarse a cabo en un intento por comprender mejor el mecanismo de progresión maligna de la QC.

PALABRAS CLAVE: Matriz extracelular; Elastina; Inmunohistoquímica; Queilitis actínica.

\section{REFERENCES}

Araújo, C. P.; Gurgel, C. A.; Ramos, E. A.; Freitas, V. S.; Barbosa, A. A. Jr.; Ramalho, L. M. \& dos Santos, J. N. Accumulation of CD1a-positive Langerhans cells and mast cells in actinic cheilitis. J. Mol. Histol., 41(6):357-65, 2010.

Cavalcante, A. S.; Anbinder, A. L. \& Carvalho, Y. R. Actinic cheilitis: clinical and histological features. J. Oral Maxillofac. Surg., 66(3):498-503, 2008.

da Silva, T. A.; Coelho, G.; Lorenzetti, B. A. \& Figueiredo Cavalcante, N. F. Expression of apoptotic, cell proliferation regulatory, and structural proteins in actinic keratosis and their association with dermal elastosis. J. Cutan. Pathol., 34(4):31523, 2007.

DeClerck, Y. A.; Mercurio, A. M.; Stack, M. S.; Chapman, H. A.; Zutter, M. M.; Muschel, R. J.; Raz, A.; Matrisian, L. M.; Sloane, B. F.; Noel, A.; Hendrix, M. J.; Coussens, L. \& Padarathsingh, M. Proteases, extracellular matrix, and cancer: a workshop of the path B study section. Am. J. Pathol., 164(4):1131-9, 2004.

dos Santos, J. N.; de Sousa, S. O.; Nunes, F. D.; Sotto, M. N. \& de Araujo, V. C. Altered cytokeratin expression in actinic cheilitis. J. Cutan. Pathol., 30(4):237-41, 2003.

Fukushima, M.; Fukuda, Y.; Kawamoto, M. \& Yamanaka, N. Elastosis in lung carcinoma: Immunohistochemical, ultrastructural and clinical studies. Pathol. Int., 50(12):100413,2000

Ge, L.; Meng, W.; Zhou, H. \& Bhowmick, N. Could stroma contribute to field cancerization? Med. Hypotheses, 75(1):2631,2010 .

Jarvelainen, H.; Sainio, A.; Koulu, M.; Wight, T. N. \& Penttinen, R. Extracellular matrix molecules: potential targets in pharmacotherapy. Pharmacol. Rev., 61(2):198-223, 2009.

Just, M.; Monso, E.; Ribera, M.; Lorenzo, J. C.; Morera, J. \& Ferrandiz, C. Relationships between lung function, smoking and morphology of dermal elastic fibres. Exp. Dermatol., 14(10):744-51, 2005.
Just, M.; Ribera, M.; Monso, E.; Lorenzo, J. C. \& Ferrandiz, C. Effect of smoking on skin elastic fibres: morphometric and immunohistochemical analysis. Br. J. Dermatol., 156(1):8591, 2007.

Knott, A.; Reuschlein, K.; Lucius, R.; Stab, F.; Wenck, H. \& Gallinat, S. Deregulation of versican and elastin binding protein in solar elastosis. Biogerontology, 10(2):181-90, 2009.

Liotta, L. A. Tumor invasion and metastases: role of the basement membrane. Warner-Lambert Parke-Davis Award lecture. Am. J. Pathol., 117(3):339-48, 1984.

Markopoulos, A.; Albanidou-Farmaki, E. \& Kayavis, I. Actinic cheilitis: clinical and pathologic characteristics in 65 cases. Oral Dis., 10(4):212-6, 2004.

Martinez, A.; Brethauer, U.; Rojas, I. G.; Spencer, M.; Mucientes, F.; Borlando, J. \& Rudolph, M. I. Expression of apoptotic and cell proliferation regulatory proteins in actinic cheilitis. J. Oral Pathol. Med., 34(5):257-62, 2005.

Miura, Y.; Fujimoto, N.; Komatsu, T.; Tajima, S.; Kawada, A.; Saito, T. \& Fujii, N. Immunohistochemical study of chronological and photo-induced aging skins using the antibody raised against D-aspartyl residue-containing peptide. J. Cutan. Pathol., 31(1):51-6, 2004.

Philips, N.; Keller, T.; Hendrix, C.; Hamilton, S.; Arena, R.; Tuason, M. \& Gonzalez, S. Regulation of the extracellular matrix remodeling by lutein in dermal fibroblasts, melanoma cells, and ultraviolet radiation exposed fibroblasts. Arch. Dermatol. Res., 299(8):373-9, 2007.

Rojas, I. G.; Martinez, A.; Pineda, A.; Spencer, M. L.; Jimenez, M. \& Rudolph, M. I. Increased mast cell density and protease content in actinic cheilitis. J. Oral Pathol. Med., 33(9):56773, 2004.

Seite, S.; Colige, A.; Piquemal-Vivenot, P.; Montastier, C.; Fourtanier, A.; Lapiere, C. \& Nusgens, B. A full-UV spectrum absorbing daily use cream protects human skin against biological changes occurring in photoaging. Photodermatol. Photoimmunol. Photomed., 16(4):147-55, 2000.

Seite, S.; Zucchi, H.; Septier, D.; Igondjo-Tchen, S.; Senni, K. \& Godeau, G. Elastin changes during chronological and photoageing: the important role of lysozyme. J. Eur. Acad. Dermatol. Venereol., 20(8):980-7, 2006.

Sgarbi, F. C.; Bertini, F.; Tera, T. M. \& Cavalcante, A. S. Morphology of collagen fibers and elastic system fibers in actinic cheilitis. Indian J. Dent. Res., 21(4):518-22, 2010.

Walther, U.; Kron, M.; Sander, S.; Sebastian, G.; Sander, R.; Peter, R. U.; Meurer, M.; Krahn, G. \& Kaskel, P. Risk and protective factors for sporadic basal cell carcinoma: results of a two-centre case-control study in southern Germany. Clinical actinic 
ARAÚJO, C. P.; XAVIER, F. C. A.; GUGEL, C. A. S.; RAMOS, E. A. G.; FREITAS, V. S.; SCHLAEPFER-SALES, C. B.; RAMALHO, L. M. P. \& DOS SANTOS, J. N. Elastin accumulation in actinic cheilitis with different degrees of epithelial dysplasia. Int. J. Morphol., 30(2):627-633, 2012.

elastosis may be a protective factor. Br. J. Dermatol., $151(1): 170-8,2004$.

Wondrak, G. T.; Roberts, M. J.; Cervantes-Laurean, D.; Jacobson, M. K. \& Jacobson, E. L. Proteins of the extracellular matrix are sensitizers of photo-oxidative stress in human skin cells. J. Invest. Dermatol., 121(3):578-86, 2003.

Xavier, F. C.; Takiya, C. M.; Reis, S. R. \& Ramalho, L. M. p63 Immunoexpression in lip carcinogenesis. J. Mol. Histol., 40(2):131-7, 2009.

Yano, K.; Kadoya, K.; Kajiya, K.; Hong, Y. K. \& Detmar, M. Ultraviolet $\mathrm{B}$ irradiation of human skin induces an angiogenic switch that is mediated by upregulation of vascular endothelial growth factor and by downregulation of thrombospondin-1. Br. J. Dermatol., 152(1):115-21, 2005.
Correspondence to:

Jean Nunes dos Santos

Faculdade de Odontologia

Federal University of Bahia

UFBA. Av. Araujo Pinho, 62, Canela

Salvador, Bahia, Zip Code: 40110-150

BRAZIL

Phone Number: 557132839019

Fax: 557132838962

Email: jeanunes@ufba.br

Received: 10-11-2011

Accepted: 11-01-2012 